\title{
Interaction effects of Zinc and Manganese on growth, uptake response and chlorophyll content of sweet corn (Zea mays var. saccharata)
}

\begin{abstract}
Manganese (Mn) and Zinc ( $\mathrm{Zn})$ interact with each other and this interaction can result in impacts on the yield of corn plants. This study was conducted to examine the effect of different levels of $\mathrm{Mn}$ and $\mathrm{Zn}$ on the yield, $\mathrm{Mn}$ and $\mathrm{Zn}$ concentration, root growth parameters and chlorophyll contents of corn plants. Sweet corn was grown in nutrient culture containing all combinations of $\mathrm{Zn}$ and $\mathrm{Mn}$ at levels of $0.0,0.1,1.0$ and $10.0 \mathrm{mg} \mathrm{L}-1$ as $\mathrm{ZnSO} 4.7 \mathrm{H} 2 \mathrm{O}$ and $\mathrm{MnSO} 4 . \mathrm{H} 2 \mathrm{O}$, respectively and harvested at 28 days after transplanting. $\mathrm{Mn}$ and $\mathrm{Zn}$ concentrations in roots and shoots increased with increasing $\mathrm{Mn}$ and $\mathrm{Zn}$ concentration in nutrient solution. $\mathrm{Zn}$ concentration in both roots and shoots enhanced with increasing $\mathrm{Mn}$ levels. Mn concentration in shoots did not show any correlation with $\mathrm{Zn}$ concentration in nutrient solution, but $\mathrm{Mn}$ concentration in roots decreased with increasing levels of $\mathrm{Zn}$. Zn0Mn1 treatment produced the highest yield. The lowest dry weight of young corn plants was recorded under $\mathrm{Zn} 10 \mathrm{Mn} 0$ treatment due to Mn deficiency. Chlorophyll content decreased with high $\mathrm{Zn}$ application and this can be attributed to the interaction of $\mathrm{Zn}$ with iron in the growth medium. Different levels of $\mathrm{Zn}$ and $\mathrm{Mn}$ in nutrient solution did not have any significant effect on root parameters.
\end{abstract}

Keyword: Zinc; Manganese; Corn; Concentration; Chlorophyll 